\title{
Anticoagulation in the treatment of portovenous emboli after cyanoacrylate injection for a bleeding gastric varix
}

\author{
Charlene Xian Wen $\underline{K w a}^{1}$, MBBs, Veronique Kiak Mien ${\underline{T a n^{2}}}^{2}$, MBBS, MRcs, Hock Soo Ong ${ }^{1}$, MBBS, FRcs
}

\begin{abstract}
We herein report the use of endoscopic n-butyl-2-cyanoacrylate injections to obliterate a gastric varix, which led to cyanoacrylate embolisation in the splenic and portal veins in a single patient. Cyanoacrylate embolisation is a known but uncommonly reported complication of endoscopic sclerotherapy. This case report illustrates the successful management of this complication (i.e. cyanoacrylate embolisation in the splenic and portal veins) with anticoagulation and analyses the presentation and management of other cases of cyanoacrylate embolisation reported in the literature.
\end{abstract}

Keywords: bleeding gastric varices, complications of sclerotherapy, cyanoacrylate emboli, treatment of portovenous emboli

\section{INTRODUCTION}

Gastric varices account for $10 \%-15 \%$ of all variceal bleeding and are an uncommon but important cause of upper gastrointestinal bleeding. (1) The use of n-butyl-2-cyanoacrylate injections to obliterate varices has been shown to be effective and is currently widely accepted as the therapy of choice for bleeding gastric varices. ${ }^{(2)}$ However, a rare but known complication of the therapy is portal embolisation of cyanoacrylate. We herein report a case of splenic and portal vein emboli after successful haemostasis of a bleeding gastric varix, and discuss the possible consequences of this complication. A review of reported cases and the use of anticoagulation in the management of our patient is also presented.

\section{CASE REPORT}

A 73-year-old man with no history of liver disease presented to our unit with a one-week history of melaena without haematemesis. His blood pressure was 99/40 $\mathrm{mmHg}$ and he had a pulse rate of 84 beats per minute. There was conjunctiva pallor and non-icteric sclerae, but no splenomegaly. Digital rectal examination confirmed the presence of melaena. Laboratory tests revealed the following: haemoglobin 8.2 (normal range [NR] 14.0-18.0) g/dL; platelet count 205,000 (NR 140,000-440,000)/ $\mu \mathrm{L}$; and normal liver function tests and coagulation screen. Serologic markers were negative for hepatitis B and C. Upper endoscopy showed a nodular gastric fundal varix with an overlying clot; the varix started to bleed profusely after the clot was dislodged. Haemostasis was secured with $2.4 \mathrm{~mL}$ of a 1:1.4 mixture of n-butyl-2-cyanoacrylate and lipiodol, administered in two injections.

After endoscopic haemostasis, computed tomography (CT) of the abdomen was performed to investigate the cause of his possible portal hypertension. CT showed the absence of liver cirrhosis, but the presence of sclerosant in the treated gastric varix. It also showed evidence of embolisation of cyanoacrylate in the main portal vein, splenic vein and liver (Fig. 1).

Doppler ultrasonographic assessment of the portal system was performed to assess portal venous flow. It showed no colour
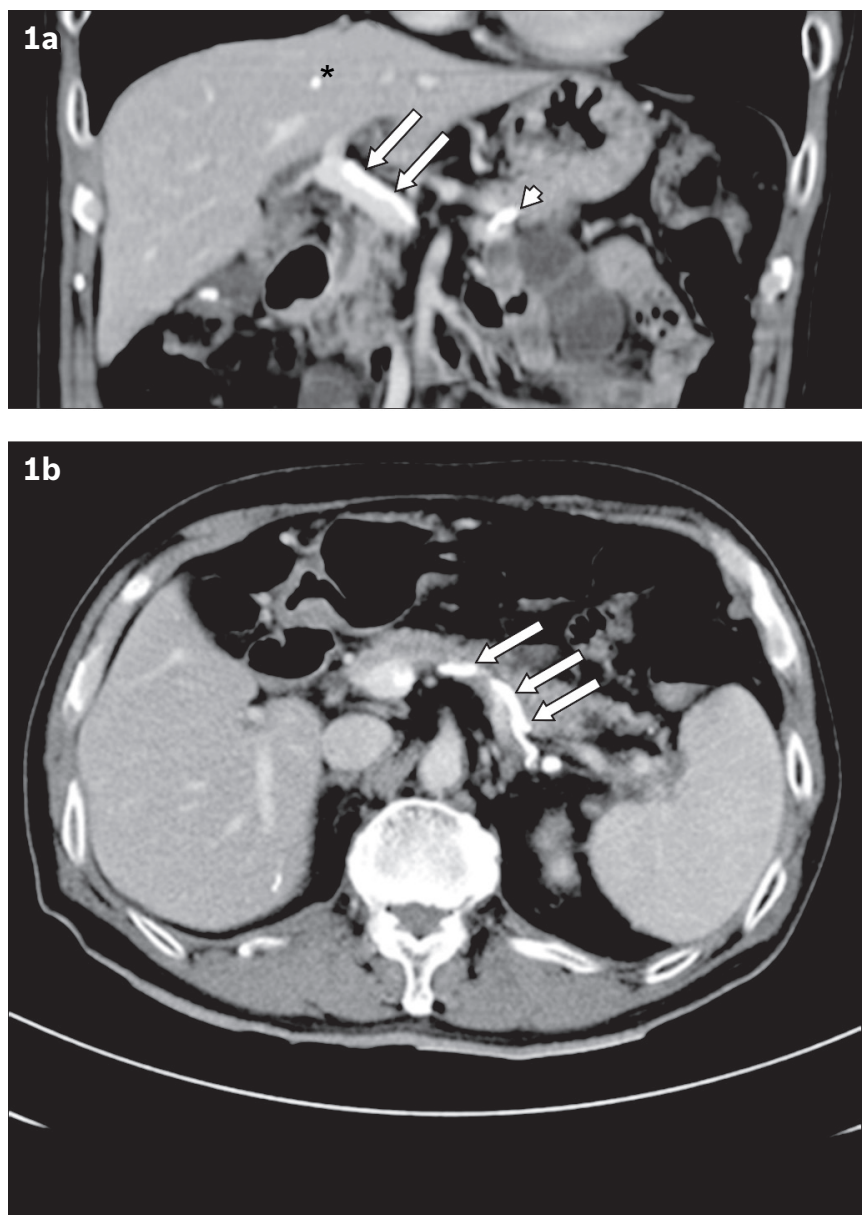

Fig. 1 Abdominal CT images one day after sclerotherapy show cyanoacrylate embolism in (a) the main portal vein (arrows), splenic vein (arrowhead) and liver (asterisk); and (b) the splenic vein (arrows).

flow at the distal portal vein, but spectral Doppler demonstrated a biphasic waveform, indicating partial blockage of the main portal vein. However, the right and left portal veins were patent and had normal phasic spectral waveforms. The patient had an isolated and transient rise of serum aspartate transaminase level to a peak of 42 (NR 15-33) IU/L. After a multidisciplinary discussion, the patient was deemed to be able to benefit from cautious

${ }^{1}$ Department of Anaesthesiology, ${ }^{2}$ Department of General Surgery, Singapore General Hospital, Singapore

Correspondence: Dr Charlene Xian Wen Kwa, Resident, Department of Anaesthesiology, Academia Level 5, Singapore General Hospital, Outram Road, Singapore 169608. Charlene.kwa@mohh.com.sg 
anticoagulation to maintain portal venous flow, in view of the thrombogenic cyanoacrylate embolus within the main portal vein. He was started on subcutaneous enoxaparin (Clexane) $40 \mathrm{mg}$ once a day for five days after sclerotherapy. No further episodes of gastrointestinal bleeding was noted; he was discharged and maintained on anticoagulation therapy for three months.

Doppler ultrasonography of the hepatic vasculature one month later showed a patent main portal vein with normal phasic waveforms. Subsequent CT imaging in six months showed no evidence of sclerosant within the main portal vein. There was minimal sclerosant in the splenic vein, which remains patent, and significantly less sclerosant in the liver parenchyma. No hepatic atrophy was noted (Fig. 2).

\section{DISCUSSION}

Bleeding from gastric varices is a life-threatening condition with a one-year mortality rate of $52 \%{ }^{(3)}$ Cyanoacrylate is an adhesive that polymerises on contact with tissue moisture to form a firm, stable mass within the varix. In the largest series (635 patients over 10 years) reported by Cheng et al, ${ }^{(4)}$ endoscopic injection of cyanoacrylate had a 95\% success rate of achieving initial haemostasis and has emerged in many centres worldwide as the initial treatment of choice for acute bleeding gastric varices. Complications of this method are rare and include the following: recurrence of bleed due to early extrusion of the glue cast (4.4\%); sepsis $(1.3 \%)$; distant emboli (pulmonary, cerebral, splenic; $0.7 \%)$; gastric ulcer formation $(0.1 \%)$; major gastric variceal bleeding $(0.1 \%)$; and mesenteric haematoma associated with haemoperitoneum and bacterial peritonitis $(0.1 \%)$. The reported complication-related mortality rate was $0.53 \%$. $^{(4)}$

Sclerosant embolisation may occur in the systemic splenic, mesenteric or portovenous circulation. Within the systemic circulation, pulmonary, cerebral and coronary embolisations have been described and such emboli may be life threatening. ${ }^{(5)}$ In contrast, a systematic review of the literature provided only five other reports of portovenous embolisations, which showed varied courses. A summary of their presentations, laboratory findings, and management and outcome are presented in Table I. From the review, it is apparent that patients with portovenous sclerosant emboli are often asymptomatic. However, acute hepatic failure necessitating a liver transplant has been documented.

Cyanoacrylate emboli within the portovenous system, if large enough, may acutely obliterate the portal vein. More commonly, it gives rise to acute or chronic portal vein thrombosis due to the thrombogenic property of cyanoacrylate. Acute portal vein thrombosis (APVT) usually presents with colicky abdominal or lumbar pain of sudden onset or progressing over a few days. Partial thrombosis may be associated with few symptoms and is commonly discovered only during radiologic examination for other reasons. ${ }^{(6)}$ The potential consequences of APVT, regardless of aetiology, include intestinal infarction and portal hypertension leading to gastrointestinal bleeding. The aim of APVT treatment is the prevention of complete thrombosis and the recanalisation of the obstructed veins. Treatment modalities that have been reported to be successful include anticoagulation

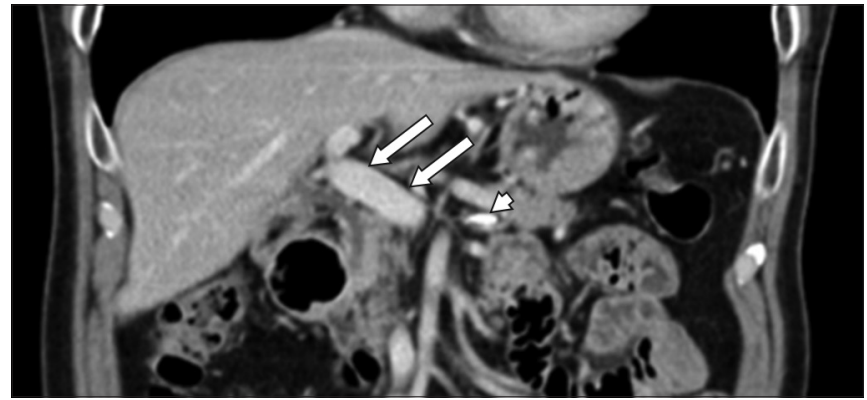

Fig. 2 Abdominal CT six months after completion of anticoagulation therapy shows patent main portal vein with no sclerosant within (arrows) and minimal sclerosant within the splenic vein (arrowhead).

and thrombolysis given into the systemic venous circulation, the superior mesenteric artery or the portal vein via the transjugular or transhepatic route. In a study by Condat et al, $90 \%$ of patients achieved some degree of recanalisation and major complications were reported in less than $5 \%{ }^{(6)}$ In contrast, the efficacy of thrombolysis is lower and mortality increased, but should be considered if initial anticoagulant therapy fails. ${ }^{(7)}$ The American Association for the Study of Liver Diseases practice guidelines recommend giving anticoagulation therapy for at least three months, starting with low-molecular-weight heparin and shifting to oral anticoagulation. ${ }^{(8)}$ Turnes et al showed that anticoagulation initiated within 30 days of the onset of symptoms was associated with recanalisation of the portal vein in about $40 \%$ of patients, compared to patients who were not anticoagulated (none achieved portal vein recanalisation). ${ }^{(9)}$ Should the obstructed veins fail to recanalise, chronic portal vein thrombosis (CPVT) may develop. The clinical manifestations of CPVT include gastrointestinal bleeding from ruptured oesophageal or gastric varices, a degree of subclinical encephalopathy, and splenomegaly. These are a result of portosystemic shunting due to portal hypertension from the obstructed portal vein. On abdominal imaging with ultrasonography or CT, the hepatopetal collaterals of CPVT appear as serpiginous structures, while the main portal vein and/or its branches are not visible. ${ }^{(10)}$

In our patient, the cause of the isolated bleeding gastric varix is unknown. It occurred in the absence of liver cirrhosis or portal hypertension, and the splenic vein was patent. The partial portal vein thrombosis was fortuitously identified early on CT while working up the cause of the gastric varix. The retrograde pattern of embolisation suggests a preexisting shunt from the left gastric vein to the splenic vein, unlike portosystemic shunts that develop in a background of portal hypertension and give rise to systemic embolisations instead. In view of the decreased portal vein flow on Doppler ultrasonography and the apparent sclerosed isolated gastric varix, we decided to cautiously start our patient on anticoagulation for three months. The role of anticoagulation in this case was to prevent propagation of intravenous thrombus and potential complete portal vein occlusion due to nonlaminar blood flow, generated by the irregular surface of the cyanoacrylate embolus while awaiting the embolus to be endothelialised. The use of anticoagulation had its associated risk of significant bleeding and our patient was closely monitored and advised to 
Table I. Presentation, management and outcome of portovenous cyanoacrylate embolism case reports in the literature.

\begin{tabular}{|c|c|c|c|c|}
\hline Study & Complication & Presentation & $\begin{array}{l}\text { Post-injection liver } \\
\text { enzymes }\end{array}$ & Management and outcome \\
\hline $\begin{array}{l}\text { Present } \\
\text { study }\end{array}$ & $\begin{array}{l}\text { Portal vein, splenic } \\
\text { vein and liver } \\
\text { embolism; partial } \\
\text { portal vein thrombosis }\end{array}$ & Incidental finding on CT scan & $\begin{array}{l}\text { Isolated and } \\
\text { transient rise of AST }\end{array}$ & $\begin{array}{l}\text { Clexane } 40 \text { mg OM for } 3 \text { months } \\
\text { and follow-up imaging; at } \\
6 \text { months, no sclerosant } \\
\text { within the main portal vein } \\
\text { and minimal sclerosant in the } \\
\text { splenic vein and liver }\end{array}$ \\
\hline $\begin{array}{l}\text { Shim } \\
\text { et } \mathrm{al}^{(11)}\end{array}$ & $\begin{array}{l}\text { Portal vein and splenic } \\
\text { vein thrombosis }\end{array}$ & $\begin{array}{l}\text { Symptomatic: left upper quadrant } \\
\text { abdominal pain and intermittent fever }\end{array}$ & Not reported & Not reported \\
\hline $\begin{array}{l}\text { Fan and } \\
\text { Soon }^{(12)}\end{array}$ & Portal vein embolism & $\begin{array}{l}\text { Incidental finding on CT } \\
\text { (investigation of postoperative fever) }\end{array}$ & Not reported & Not reported \\
\hline $\begin{array}{l}\text { Lee } \\
\text { et } \mathrm{al}^{(13)}\end{array}$ & Portal vein embolism & $\begin{array}{l}\text { Hepatic failure with massive ascites; } \\
\text { diagnosis confirmed on microscopy } \\
\text { of explanted liver }\end{array}$ & Elevated AST and ALT & Liver transplant \\
\hline $\begin{array}{l}\text { Korula } \\
\text { et } \mathrm{al}^{(14)}\end{array}$ & Portal vein thrombosis & $\begin{array}{l}\text { Incidental finding at subsequent } \\
\text { surgery for portocaval shunt }\end{array}$ & Not reported & $\begin{array}{l}\text { Thrombectomy and } \\
\text { endovenectomy of portal vein }\end{array}$ \\
\hline $\begin{array}{l}\text { Shih } \\
\text { et } \mathrm{al}^{(15)}\end{array}$ & Portal vein embolism & $\begin{array}{l}\text { Incidental finding on abdominal } \\
\text { radiography (routine follow-up) }\end{array}$ & $\begin{array}{l}\text { Slightly elevated } \\
\text { levels of total } \\
\text { bilirubin and AST }\end{array}$ & $\begin{array}{l}\text { Followed up conservatively } \\
\text { for two years; atrophy of left } \\
\text { lateral segment of liver, portal } \\
\text { vein thrombosis and little } \\
\text { residual lipiodol retention, but } \\
\text { no evidence of liver failure }\end{array}$ \\
\hline
\end{tabular}

ALT: alanine aminotransferase; AST: aspartate aminotransferase; CT: computed tomography; OM: once in the morning

return should symptoms of bleeding occur. Close follow-up with Doppler ultrasonography and CT was instituted. In our patient, the emboli resolved uneventfully and CPVT was avoided. To our knowledge, this is the first case with main portal vein embolisation secondary to cyanoacrylate sclerotherapy treated as such.

\section{REFERENCES}

1. Sarin S, Lahoti D, Saxena SP, Murthy NS, Makwana UK. Prevalence, classification and natural history of gastric varices: a long-term follow-up study in 568 portal hypertension patients. Hepatology 1992; 16:1343-9.

2. Greenwald BD, Caldwell SH, Hespenheide EE, et al. N-2-butylcyanoacrylate for bleeding gastric varices: a United States pilot study and cost analysis. Am J Gastroenterol 2003; 98:1982-8.

3. Ogawa K, Ishikawa S, Naritaka Y, et al. Clinical evaluation of endoscopic injection sclerotherapy using n-butyl-2-cyanoacrylate for gastric variceal bleeding. J Gastroenterol Hepatol 1999; 14:245-50.

4. Cheng LF, Wang ZQ, Li CZ, et al. Low incidence of complications from endoscopic gastric variceal obturation with butyl cyanoacrylate. Clin Gastroenterol Hepatol 2010; 8:760-6.

5. Saracco G, Giordanino C, Roberto N, et al. Fatal multiple systemic embolisms after injection of cyanoacrylate in bleeding gastric varices of a patient who was noncirrhotic but with idiopathic portal hypertension. Gastrointest Endosc 2007; 65:345-7.

6. Condat B, Pessione F, Helene Denninger M, Hillaire S, Valla D. Recen portal or mesenteric venous thrombosis: increased recognition and frequent recanalization on anticoagulant therapy. Hepatology 2000; 32:466-70.

7. Hollingshead M, Burke CT, Mauro MA, et al. Transcatheter thrombolytic therapy for acute mesenteric and portal vein thrombosis. J Vasc Interv Radiol 2005; 16:651-61.

8. DeLeve LD, Valla DC, Gracia-Tsao G. Vascular disorders of the liver. Hepatology 2009; 49:1729-64.

9. Turnes J, García-Pagán JC, González M, et al. Portal hypertensionrelated complications after acute portal vein thrombosis: impact of early anticoagulation. Clin Gastroenterol Hepatol 2008; 6:1412-7.

10. Kreft B, Strunk H, Flacke S, et al. Detection of thrombosis in the portal venous system: comparison of contrast-enhanced MR angiography with intraarterial digital subtraction angiography. Radiology 2000; 216:86-92.

11. Shim CS, Cho YD, Kim JO, et al. A case of portal and splenic vein thrombosis after Histoacryl injection therapy in gastric varices. Endoscopy $1996 ; 28: 461$.

12. Fan CS, Soon MS. Portal vein embolization as a complication of Histoacryl injection for a bleeding giant gastric ulcer. Endoscopy 2007; 39 Suppl 1:E110

13. Lee KM, Kim YB, Sin SJ, et al. Hepatic failure requiring transplantation caused by portal vein embolism as a complication of $\mathrm{N}$-buty-2-cyanoacrylate injection for a bleeding gastric varix. Gastrointest Endosc 2009; 69:967-9.

14. Korula J, Yellin A, Kanel GC, Nichols P. Portal vein thrombosis complicating endoscopic variceal sclerotherapy. Convincing further evidence. Dig Dis Sci 1991; 36:1164-7.

15. Shih KL, Yen HH, Soon MS. Portal-vein embolization after sclerotherapy treatment of bleeding gastric varices: report of a case with long-term follow-up. Gastrointest Endosc 2009; 69:1176-8. 